\title{
How to Prevent Recurrent Morbidity During Thyroidectomy for Giant Goiter
}

\author{
Koné Fatogoma Issa*, Soumaoro Siaka, Haïdara Abdoul Wahab, Cissé Naouma, Diarra Kassim, Konaté N’faly, \\ Singaré Kadidiatou, Guindo Boubacary, Timbo Samba Karim, and Mohamed Amadou Kéïta
}

Department of ENT-Head and Neck Surgery, Mali

*Corresponding author: Koné Fatogoma Issa, Department of ENT-Head and Neck Surgery, Mali

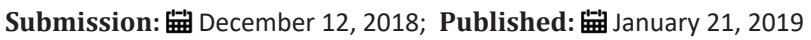

Summary

Objective: We brought elements contributing to the rationalization of a strategy of the recurrent nerve that could contribute to the reduction of postoperative complications.

Material and method: This is a descriptive and retrospective study of a series of 14 cases of giant goiter, collected in the Department of Otorhinolaryngology and Head and Neck Surgery of Gabriel Touré University Hospital. Bamako. It has been spread over a period of 3 years from June 2016 to June 2018. We included the weight of the surgical specimen was greater than or equal to $500 \mathrm{mg}$ and whose mobility of the larynx is preserved preoperatively. The superior approach was the original way of dissection. The cricopharyngeal muscle was the essential marker.

Results: In 3 years, we collected 14 cases of giant goiter, during this period we performed 118 thyroidectomies, a rate of $11.86 \%$ of cases. The postoperative complications were noticed in a case of the hematoma of the lodge (7.1\%), the release from the operation (7.1\%), and the superinfection is $7.1 \%$. Signs of hypothyroidism were found in $21.4 \%$ of cases. No recurrent laryngeal nerve lesion was observed.

Conclusion: Giant goiters are a surgical entity not supported by current recommendations. The surgeon is confronted with this entity must implement his anatomical and histological knowledge for a proper grip. A superior approach of the recurrent nerve and bloodless surgery is a guarantee of a good prognosis.

Keywords: Thyroidectomy; Giant goiter; Superior approach

\section{Introduction}

Thyroid surgery has a privileged place in the treatment of multiple thyroid diseases, especially in cases of thyroid cancer, but also bulky nodule, compressive goiter, plunging or toxic [1]. It is up to the surgeon to set up a protocol for surgical management, this requires a multidimensional approach to:

The anatomy of the neck and the path of the recurrent nerve.

The left RLN loops under the aorta medially and ascends the trachea-oesophageal groove. He is approximately $12 \mathrm{~cm}$ from the aorta to the cricothyroid joint. The recurrent nerve can pass under, anterior or between the branches of the lower thyroid artery [2]. The right RLN is a shorter nerve at five to six centimetres from the subclavian to the cricothyroid joint. As the right vagus nerve courses along the common carotid artery, at the division of the innominate artery the right RLN loops around the subclavian artery and travels along the right superior lobe pleura. It enters the trachea-oesophageal groove more laterally than the left side behind the common carotid artery [2].

1. The possibilities to approach the recurreexnt nerve and the parathyroid.
2. The anatomical variations of the recurrent nerve to know how to overcome the pitfalls.

3. An understanding of endocrine phenomena to appreciate the symptoms.

4. Pathological varieties of tumor [3].

Analysis of the literature data revealed significant postoperative morbidity in some series [4]. Recurrent paralysis is a frequent complication and is the major fear of surgeons with giant goiter. The nosology of giant goiter remains a subject little discussed by the literature $[1,5]$. The recurrent approach is a problem of integration efficiency in the management of giant goiters. The multiplicity of the ratio of the thyroid gland with the other neighboring organs and the development of a giant goiter in this restricted cervical space is the corollary of the phenomena of compression and difficult intubation $[1,5]$. In view of the problem raised by the management of giant goiters by surgeons, we brought elements contributing to the rationalization of a recurrent laryngeal nerve dissection technique that could contribute to the reduction of postoperative complications. 


\section{Materials and Methods}

This is a descriptive and retrospective study of a series of 14 cases of giant goiter, collected in the Department of Otorhinolaryngology and Head and Neck Surgery of Gabriel Touré University Hospital. Bamako. It has been spread over a period of 3 years from June 2016 to June 2018. Patients with giant goiter were first concerned.

We included all patients of all ages operated for a giant goiter at the ENT department of Gabriel Toure University Hospital where the weight of the surgical specimen was greater than or equal to $500 \mathrm{mg}$ and whose mobility of the larynx is preserved preoperatively. Inoperable records, non-operated patients and thyroid cancers. The studied variables concerned the socio-demographic status, the clinical aspect, the Para clinical data and the histological examination of the operative specimen.

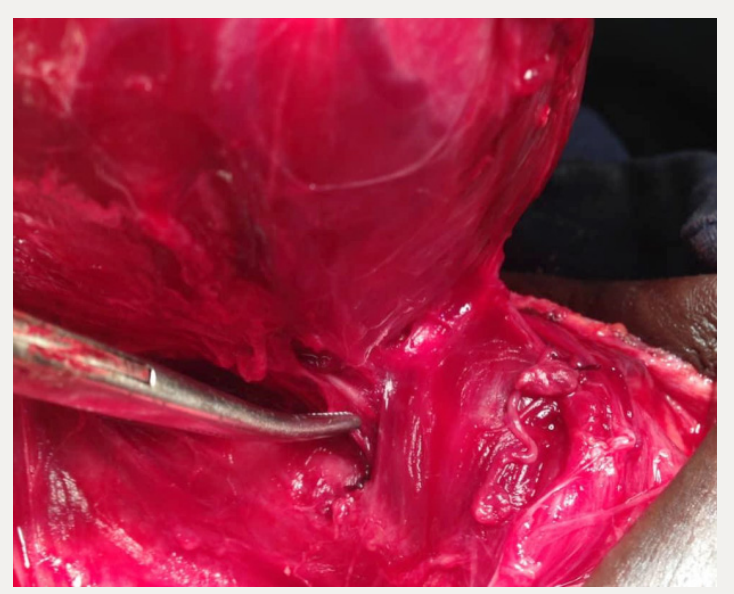

Figure 1: The left recurrent laryngeal nerve at the point of entry into the larynx.

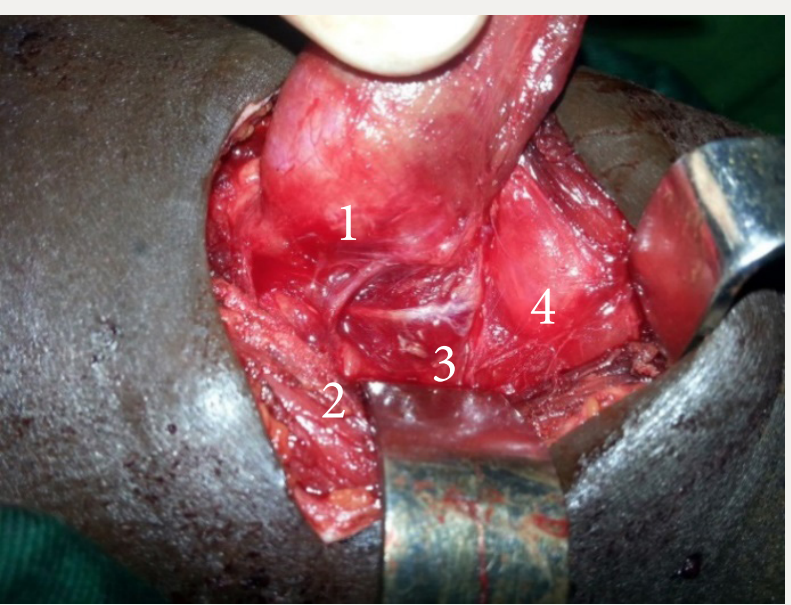

Figure 2: Superior approach of left recurrent laryngeal nerve.
1: Thyroid lobe
3: Recurrent laryngeal nerve
2: Inferior thyroid artery
4: Cricopharyngeal muscle

Patients who underwent total thyroidectomy received thyroid hormone supplementation. Our data was computerized using software specialized in statistical processing "SPSS 21.0 French version", and the data entry on Word 2013. The Surgical Technique (Figure 1-3). The first step is that of a classic Kocher type incision over 6 to $10 \mathrm{~cm}$ depending on the size of the goiter. After the medial aponevrectomy and exposure of the thyroid gland. The first step is the ligation of the vessels of the upper pole after opening the white line. The cricopharyngeal muscle is carefully exposed. Our recurrent search is carried out in a triangle bordered at the bottom by the lower edge of the muscle and at the top the thyroid lobe. The release and preservation of the superior parathyroid will give a lateral space with a wide view over the search area. The upper pole put in traction by a wire and pulled up and out. Recurrent research is made with the understanding that the nerve has a lateral path to the right trachea and is in the tracheal angle. Once the nerve is identified, a puncture-dissection is performed without any real contact with the nerve. The closure is done in two planes on drain: the fascia and the skin in separated simple points. We did not use any nerve monitoring.

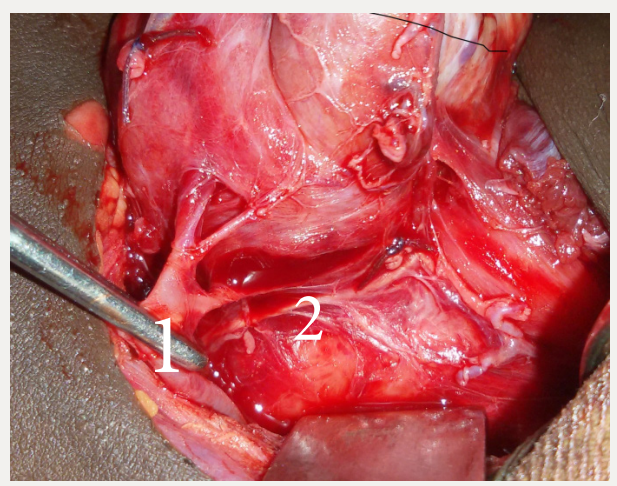

Figure3: Recurrent laryngeal nerve after dissection.

1. The lower thyroid artery which is divided into three branches.

2. The left recurrent laryngeal nerve.

\section{The Results}

In 3 years we collected 14 cases of giant goiter, during this period we performed 118 thyroidectomies, a rate of $11.86 \%$ of cases. The average age was 50.71 years old with extremes ranging from 37 to 66 years. Female patients were common in $64.3 \%$ of cases with a sex ratio of 0.56 . The average age of evolution was 25.3 years with extremes ranging from 7 to 40 years (Table 1). Signs of compression had concerned cases of dyspnea, dysphagia and dysphonia (Table 2). Endolaryngeal examination was normal in all patients, there was no cervical lymphadenopathy. The lower dipping pole was found in 5 cases on CT scan. All our patients were euthyroid. The classification of TIRADS 2 was found in $71.5 \%$ of cases, TIRADS 3 in $21.4 \%$, TIRADS 4 in $7.1 \%$. Total thyroidectomy was common in $78.6 \%$ of cases, loboisthmectomy in $21.4 \%$. The extreme weight was $500 \mathrm{~g}$ and $800 \mathrm{~g}$ with an average of $585.7143 \mathrm{~g}$. The average mensuration was $11 \mathrm{~cm}$ with extremes ranging from $8-14 \mathrm{~cm}$ (Figure 4). The operative incident was noted in three cases it was the internal jugular vein wound in $21.4 \%$ of cases. The histological type concerned the colloid adenoma of the thyroid in $100 \%$ of cases. The postoperative complications were noticed 
in a case of the hematoma of the lodge (7.1\%), the release from the operation $(7.1 \%)$, and the superinfection is $7.1 \%$. Signs of hypothyroidism were found in $21.4 \%$ of cases. No recurrent nerve lesion was observed.

Table 1: Duration of goiter.

\begin{tabular}{|c|c|c|}
\hline Duration of Evolution / Year & Effectives & Percentage \\
\hline 7 & 1 & 7,1 \\
\hline 8 & 1 & 7,1 \\
\hline 10 & 2 & 14,3 \\
\hline 15 & 2 & 14,3 \\
\hline 16 & 1 & 7,1 \\
\hline 20 & 3 & 21,4 \\
\hline 22 & 1 & 7,1 \\
\hline 25 & 2 & 14,3 \\
\hline 40 & 1 & 7,1 \\
\hline Total & 14 & 100,0 \\
\hline
\end{tabular}

Table 2: Compression sign.

\begin{tabular}{|c|c|c|}
\hline Sign & Effectives & Percentage \\
\hline Isolated dysphonia & 1 & 7.1 \\
\hline Isolated dysphagia & 2 & 14.3 \\
\hline Isolated dyspnea & 4 & 28.6 \\
\hline Dysphagia + Dyspnea & 4 & 28.6 \\
\hline Dysphagia + dyspnea + dysphagia & 1 & 7.1 \\
\hline Total & 12 & 85.7 \\
\hline
\end{tabular}

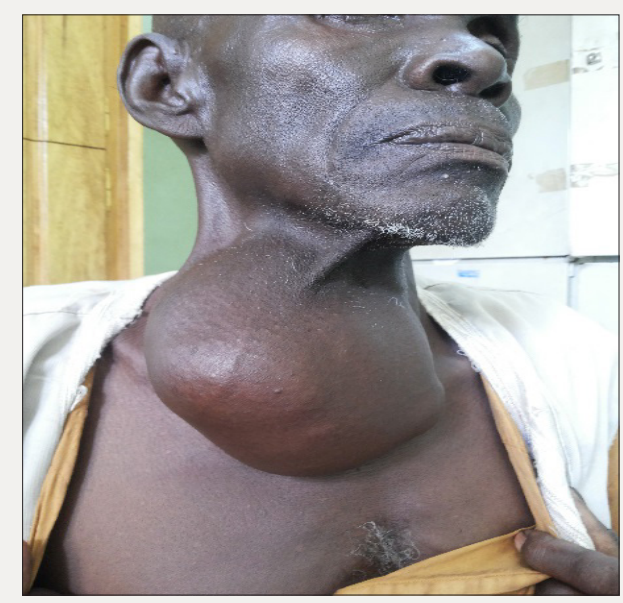

Figure 4: Giant goiter.

\section{Discussion}

The frequency of giant goiters is poorly reported in the literature [4]. Our study reported a frequency of $11.86 \%$ of cases. This observation highlights the rarity of cases of giant goiter [6]. The age of evolution of goiter has been more than 20 years in $53 \%$ of cases and according to Makeieff has been 25\% for 15 years, in $25 \%$ of cases for over 30 years and in $25 \%$ of cases since one year [4]. The long evolution time has been 40 years in our series.
The development of the goiter in the restricted space of the neck subjected the patient to compression phenomena of the respiratory, vascular, digestive and neurological organs. However, signs of compression due to the development of the goiter have been reported with dysphagia and dyspnea of decubitus as of other series [4]. The characteristics of the swelling, the associated signs and the laryngeal mobility make it possible to direct the ENT surgeon to make histological hypotheses. Dysphonia or dyspnea can tell if the nerve damage is uni or bilateral. In the case of unilateral laryngeal diplegia, the main symptom is dysphonia. On the other hand, when the diplegia laryngea is bilateral, dyspnea is the main symptom.

The volume of the goiter can change the operative sequence. The problems associated with diving and giant goiter are of a recurrent and parathyroid nature. The prevention of recurrent morbidity is an imperative for any surgeon. In the framework of the prevention of recurrent morbidity, several accesses to the recurrent nerve are described [7]. We opted for retrograde dissection of the recurrent nerve or the superior approach in the absence of a recommendation on this subject. The volume of goiter was an obstacle in our case to externalize the gland on the median line finally to carry out the recurrent search. This exposure puts the nerve under tension with the risk of stretching and traction on the nerve $[8,9]$. This risk is accentuated when the goiter has a lower extension plunging as we found in our case to CT scan. Several authors have agreed to define indications of a top approach of a recurrent nerve such as goiter goiters, bulky, thyroid recurrence and in cases where the classical way is impossible for other technique [8,9]. For some this approach can be extended to any type of thyroidectomy [8]. The easiest approach of the upper pole in case of goiter.

Our operative difficulties concerned the presence of nerve intertwined in the fibrous meshes of the ligament of Berry, the presence of extra laryngeal divisions. The difficulties were found by other authors which makes this technique dangerous hence the restriction of these indications [8,9]. Hemorrhage at the point of entry into the larynx by accidental injury to the posterior branch of the inferior thyroid artery and three cases of injury to the internal jugular vein was the obsession in our study. These are goiters that compressed the vasculo-nervous axis with adherence to a thyroid capsule. Several factors explain the hemorrhagic risk of giant goiter. These include hyper vascularization of the thyroid parenchyma, more pronounced dilation of the peripheral vessels, the very close relationship with the jugular carotidian axis and overflow on the aortic arch [1,10]. The operative sequences in some cases were enameled with hypothyroidism. Total thyroidectomy exposes the same risk of mortality and morbidity as the subtotal and would prevent the risk of recurrence in a tumor [11]. In our series hypothyroidism following total thyroidectomy is the illustration of treatment nonobservance due to low income of the population. No case of recurrent paralysis was noticed in our case as for Page C [9].

\section{Conclusion}

Giant goiters are a surgical entity not supported by current recommendations. The surgeon is confronted with this entity must implement his anatomical and histological knowledge for a proper 
grip. This management must allow the prevention of recurrent morbidity through a superior approach of the recurrent nerve, and bloodless surgery is a guarantee of a good prognosis.

Conflict Interest: The authors declare no conflict of interest.

\section{References}

1. Tran Ba Huy P, Kania R (2004) Thyroïdectomie. Encycl Med Chir Chir 3 (1) : 187-210.

2. O'Neill JP, Fenton JE (2008) The recurrent laryngeal nerve in thyroid surgery. Surgeon 6(6) : 373-377.

3. Clémençot A, Jnana M, Koszutski M (2018) Détresse respiratoire aiguë: un cas de goitre thyroïdien compressif. Journal Européen des Urgences et de Réanimation Elsevier Masson 30: 38-40.

4. Makeieff M, Marlier F, Khudjadze M, Garrel R (2000) Les goitres plongeants. À propos de 212 cas. Ann Chir 125: 18-25.

5. Duron F et Dubosclard E (2000) Goitres simples Encycl Méd Chir (Editions Scientifiques et Médicales Elsevier SAS, Paris, tous droits réservés), Endocrinologie-Nutrition 10.
6. Colack T, Akca T, Kanik A, Yapici O, Aydin S, et al. (2004) Total versus subtotal thyroidectomy for the management of benign multinodular goiter in an endemic region. Anz J Surg 74(11): 974-978.

7. Richer Sara L, Randolph Gregory W (2009) Management of the recurrent laryngeal nerve in thyroid surgery. Operative Techniques in Otolaryngology $20: 29-34$.

8. Guerrier B, Zanaret MC, Guy LE, Santini J (2006) Les différents types de chirurgie. Dans: Chirurgie de la thyroïde et de la parathyroïde. Amplifon Italie. $57-132$

9. Page C, Peltier J, Charlet L, Laude M, Strunski V (2006) Superior approach to the inferior laryngeal nerve in thyroid surgery: anatomy, surgical technique and indications. Surg Radiol Anat 28(6): 631-636.

10. Benbakh M, Abou-elfadl M, Rouadi S (2016) Goitres plongeants: expérience du service à propos de 50 cas. Annales françaises d'otorhino-laryngologie et de pathologie cervico-faciale 133: 17-20.

11. Dener C (2002) Complications rates after operations for benign thyroid disease. Acta Otolaryngol 4: 1090-1096.
Creative Commons Attribution 4.0 International License

For possible submissions Click Here

\section{Submit Article}

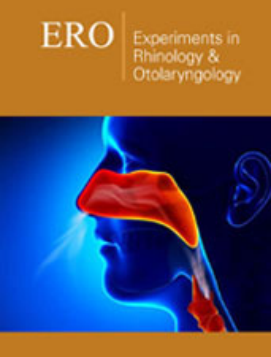

Experiments in Rhinology \& Otolaryngology

\section{Benefits of Publishing with us}

- High-level peer review and editorial services

- Freely accessible online immediately upon publication

- Authors retain the copyright to their work

- Licensing it under a Creative Commons license

- Visibility through different online platforms 